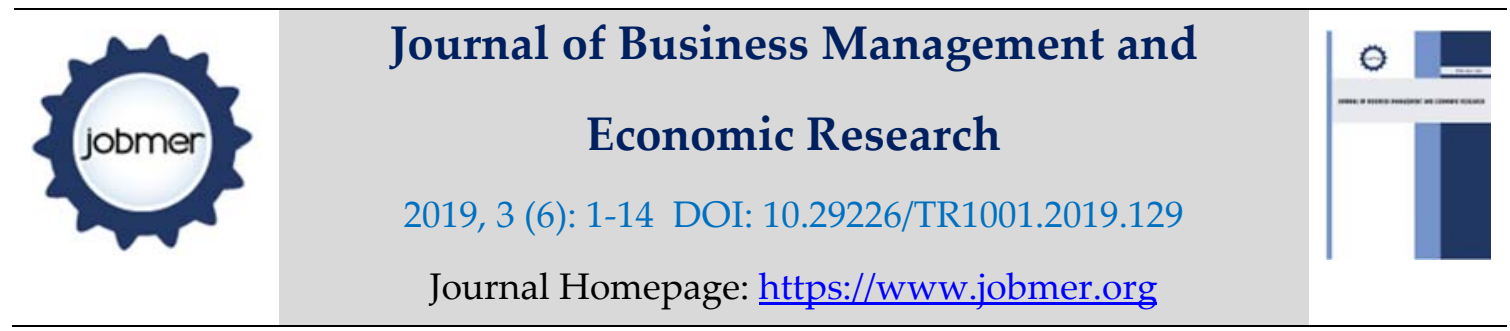

\title{
Academic Staff Motivation and Retention in Higher Learning Institutions in Tanzania: Evidence from Selected Universities in Iringa Region
}

\author{
Hadija Matimbwa \\ Ruaha Catholic University \\ hadija.matimbwa@gmail.com \\ Dr. Alexander Ochumbo \\ Ruaha Catholic University
}

\begin{abstract}
The purpose of the study was to determine the factors affecting academic staff motivation and retention among selected universities in Iringa Municipal Council. The study assessed motivational and retention strategies employed by selected universities in retaining academic staff. It determined whether there is staff motivation and retention policy among the selected universities in the region. The study also analyzed whether motivation and retention policies are effectively implemented among the selected universities in Iringa Municipal Council. This study used quantitative approach and adopted case study design to establish factors affecting academic staff motivation and retention among the selected universities. Questionnaires were used as the survey instrument. Stratified random sampling technique was used to select respondents from the entire population. Then non probability sampling was used to select a representative sample from each stratum. A sample size of 100 was drawn from the study population. The data were collected by using structured questionnaires. Descriptive statistics and inferential statistics were used to analyze data collected from the respondents and SPSS version 20 and excel Microsoft application were used to process data. Findings on the factors affecting academic staff motivation and retention revealed that work environment, promotional practices, feedback system, recognition and appreciation, training and
\end{abstract}


development have weighted mean above the neutral point (3) while orientation and induction, intention to stay, academic staff expectation and motivation and retention strategies have weighted mean below the neutral point. Upon measuring the strategies, regression were employed, and findings depict that clear career path, job security, promotion opportunities were found to have a strong effect on academic staff retention with coefficient value of $0.5482,0.4820$ and 0.4263 respectively. These findings imply that the majority of respondents consider these three strategies as important compared to others; they thought security and clear career path will make them to stay long in these universities. The majority $73 \%$ pointed out that if these retention and motivation policies are not implemented accordingly, they would be forced to quit. Only $27 \%$ of all respondents agreed that these policies are implemented accordingly.

Keywords: Motivation, Retention, Academic Staff, Universities

\section{Background}

The most valuable asset available to an organization is its people, therefore retaining employees in their jobs is essential for any organization. Indeed there is a paradigm shift from human resource to human capital which consists of the knowledge, skills and abilities of the people employed in an organization which is indicative of their value (Armstrong, 2009). Therefore, when employees leave their jobs, it is often a sign that something is going wrong.

The majority of higher learning institutions worldwide have been experiencing increasing rate of academic staff turnover. Growth in global mobility and shifting demographic profiles, means recruiting and retaining talented and knowledgeable lecturers and researchers is an ever-increasing challenge (Bernard, 2012). An achievement of universities strategic goals strongly depend on the capacity to attract, retain and maintain competent and satisfied staff into its employment. Thus, every organization or institution wants to have a competitive edge in order to attract more students and potential employees. Therefore, the demand for employees has increased and organizations are competing to attract and retain the best talent.

According to Zhou and Volkwein (2004), the costs of academic staff turnover or the cost of failure to retain academic staff are as follows; subsequent recruiting expenses, disruptions of course offerings, discontinuities in departmental and students planning especially to those staff who leave their job in 
mid-semester period, and loss of student graduate advisors are borne at individual, departmental and institutional levels. There is also impact on quality of services and the image of the institution as well; to the remaining academic staff it increases workload during the period of replacement process (that is recruitment, interview, selection and placement) and also failure to maintain the productive organizational culture.

Bernard (2012) underlines that employees' retention posits one of the greatest challenges in many organizations let alone, academic institutions world-wide, in contemporary times. There is a growing global interest in matters of recruitment and staff retention in higher education institutions. Demand and competition for highly qualified academics has intensified. From the researchers' observation, poor job retention among employees is not just the associated cost of recruitment, but also training new starters and the additional burden on remaining staff while the new team members get up to speed which further strains daily activity. Yousaf (2010) observes that the difficulties of academic staff retention within the industrialized countries are well documented. In the United States, for example about $7.7 \%$ of the full time academic staff left their institutions for other places within one academic year from 1997 to 1998, of these only $29 \%$ were retirees, the remaining $71 \%$ left due to variety of reasons. A year 2000 survey of full time faculty members in the US showed that more than $40 \%$ of them had contemplated changing careers.

The African continent faces a huge challenge in terms of skilled human resource capacity, which has a debilitating effect on its ability to make pace in the areas of socio-economic and political development (World Bank, 2006). For example: Tettey (2006) points out that Ghanaian universities and polytechnics have staff vacancy rates of $40 \%$ and $60 \%$ respectively, also "by 2000 the University of Ghana's medical school had lost about half of its teaching staff. In Nigeria, two-thirds of its 36,134 academic staff positions remain unfilled. Organizational productivity is also one of the challenges that arise as a consequence of turnover. The Strategic Plan Report (2004 - 2008: 19) recognized that Polytechnic of Namibia (PoN) has high staff turnover. Even the World Bank report (2005: 66) acknowledge that PoN find it challenging to recruit and retain staff members and lose them owing to high salaries that are offered in the private and public sector, which tempts the best brains from the institution. A study by Naris and Ukpere (2010) on developing a retention strategy for qualified staff at the Polytechnic of Namibia observes that every educational institution wants to have a competitive edge in order to attract more students and potential employees. It is through retention 
of academic staff that they will be able to have competitive advantage by ensuring continuity in provision of quality services and products. Lack of employees' continuity involves high costs in the induction and training of new staff.

In Tanzania, just like in many African and East African countries like Uganda, retention of academic staff in HLIs is low as evidenced by the following studies: a study by Abeli (2010) discovered that Sokoine University of Agriculture, had over the past 20 years lost over 90 senior staff to other Institutions while at the University of Dar es Salaam (UDSM), over 50 senior staff are on leave without pay. Kiunsi (2008) in his study at the University of Dar es Salaam also found retention of staff is low resulting from poor work conditions, low salary, lack of promotion and growth, and uninteresting work among other factors. Clearly, unless something is done to enhance the ability of these institutions to attract and to retain the requisite levels of academic staff, the situation can only get worse. The current study therefore, sought to find out whether the causes for academic staff drop out is due to poor rewarding system, unsteady promotion practices, training and development, lack of recognition and appreciation, unmet expectations, poor feedback system, and poor working conditions. Since the study considers academic zone as a core function of the universities, it also attempts to make critical and systematic analysis of the situation prevailed in relation to motivation and retention of academic staff in order to suggest remedies for the problem under study. That is to say the study focused into finding out what should be done in order to motivate and retain academic staff in Higher Learning Institutions in Tanzania with the aim of improving quality of education.

\section{Literature Review}

\subsection{Factors influencing employee motivation and Retention}

Staff retention is of interest to employers because of the implications of high staff turnover. Dibble (1999) argues that retention of employees needs to be managed and identifies remuneration, development, career opportunity, work environment, performance management and work, family and flex time as areas that have an effect on retention of employees. Studies have identified an array of factors that influence employee retention. Gaiduk et al., (2009) observed that previous studies have found that employee intentions to remain with an organization are influenced by three major groups of variables which are: employee personal characteristics such as gender, age, position level; the nature of an employee's current job; and adequate working arrangements including such aspects as 
the quality of current supervision, opportunities for promotion, available training, and quality of communication within the organization.

A study of 139 academics from Jordanian University, Al- Omari et. al.,(2009) established that job satisfaction and organizational commitment had a significant positive effect on intention to stay among the academic staff. A study by Daly et. al., (2006) on turnover intention of academics in public urban universities, established that structural factors such as faculty work environment, autonomy, communication, distributive justice and workload were related to intent to stay. This study therefore, seeks to find out what should be done to motivate and retain academic staff in higher learning institutions in Tanzania.

A study by Mayer (2006) on retention of employees in Australia discovered that young academic staff members' reasons for leaving are a bit different. Their decisions to leave range from workload; lack of input in decision making; wanting new challenges; teaching out of field; insufficient autonomy; poor salary; and personal circumstances. The study discovered that workload was cited as the highest, while salary was the least motivating factor for resigning. Metcalf, Rolfe, \& Weale, (2005) research output identified pay and fringe benefits (pension and gratuity, comparative pay levels, pay systems, pay discrimination), intrinsic aspects of the job (e.g., for academics, teaching and research), job security, work organization, autonomy, progression (changes in career paths, internal promotion, promotion criteria, and the working environment etc) as critical to academic staff retention. Unlike the current study aims not only to examine the factors affecting academic staff motivation and retention among the universities in Iringa region in Tanzania but also to find out what should be done to motivate and retain academic staff in higher learning institutions. Another study on retention of employees in Australian Organizations, Chew (2004) established that younger employees focused on remuneration, training and development, career advancement, challenging work, growth opportunities and recognition. For older employees autonomy, opportunities to mentor and job challenge were of great importance. However, current study aims at examining the factors affecting academic staff motivation and retention in Tanzania's higher education institutions in order to find out what should be done to motivate and retain academic staff in higher learning institutions in Tanzania.

A study by Sandhya and Kumar (2011) in India concludes that employee motivation is one of the important factors that can help the employer to improve employee and organizational performance. 
Different theories of motivation are discussed. The paper concludes that employee retention can be practiced better by motivating the employees in the following aspects: Open communication, Employee reward program, Career development program, Performance based bonus, Recreation facilities, Gifts at some occasions. Also, a study which was conducted by Samwel and Chipuza (2013), on attrition and retention of senior academics at institutions of higher learning in South Africa, the study adopted survey research method using quantitative research design. A self-administered questionnaire was used to gather primary data from respondents. The study examined the influence of certain work attributes on the retention of 255 senior academic staff in 10 universities across South Africa. Results of the study indicate that most of the respondents place greater importance on challenging work, inter-personal relationship, access to research resources and job security. However, this study seeks to find out what should be done to motivate and retain academic staff in higher learning institutions in Tanzania

A study conducted by Bushe, Chiwira, and Chawawa (2012), on the impact of academic staff recruitment, development and retention policies at Ba Isago University College on their commitment to the College it was found that, all tertiary institutions are confronted with the tremendous challenge of identifying, recruiting and retaining high caliber staff, particularly lecturers. These trends have engendered a more strategic approach to human resource management across the higher education sector. Staff recruitment is centralized at Gaborone Head Office for BA ISAGO University College and is mainly done through advertisement. Statistical Package for Social Scientist (SPSS) was used in the analysis of data and the stratified random sampling technique was employed. Use was made of measures of central tendency, dispersion, $\mathrm{t}$ - tests and Analysis of Variance (ANOVA). At least 70\% of the academic staff was less than 2 years of employment and $40 \%$ got their offer letters within a period of less than one week. $60 \%$ consider recruitment methods to be at least good and $77 \%$ said management is not doing enough to keep the employees motivated. Nationality and Location had no significant influence on Human Resources (HR) policies with Gender having significant impact on Staff Retention policies. Staff Motivation had a significant positive relationship with recruitment, selection and retention policies with staff retention policies having the highest positive relationship $(\mathrm{r}(31)=.673 ; \mathrm{p}<.01)$ with staff motivation. The current study seeks to find out what should be done so as to motivate and retain academic staff in higher learning institutions. 
A study of academics in Makerere University, Amutuhaire (2010) established that remuneration and tenure influenced their retention. Locally, Kipkebut (2010) in a study on organisational commitment and job satisfaction of employees in universities in Kenya established that role conflict, promotional opportunities, age were some of the factors that influenced employee intention to quit the university. These findings reflect a mixture of intrinsic and extrinsic factors. The current study aims at finding out what should be done to motivate and retain academic staff in higher learning institutions in Tanzania. A study on examining the relationship between motivation and retention of academic staff in selected public higher institutions of learning in Dar es-salaam by Oyangi and Kembu (2014) which used cross-sectional survey and correlation research design adopting a quantitative and qualitative approach. Target population of 4257 where by a sample of 210 respondents was used. Stratified and Simple random sampling was used. Findings of the study revealed that there was a strong positive relationship between motivation and retention of academic staff. The current study therefore, seeks to find out what should be done to motivate and retain academic staff motivation in higher learning institutions in Tanzania.

\section{Research Methodology}

This study used quantitative approach. This study adopted case study design to establish factors affecting academic staff motivation and retention among the selected universities. Questionnaires were used as the survey instrument. Stratified random sampling technique was used to select respondents from the entire population. Then non probability sampling was used to select a representative sample from each stratum. A sample size of 100 was drawn from the study population. The data were collected by using structured questionnaires. Descriptive statistics and inferential statistic were used to analyze data collected from the respondents and SPSS version 20 and excel Microsoft application were used to process data.

\section{Results}

\subsection{Respondents Demographic Characteristics}

Profiles of respondents considered include; Gender, Age, and academic rank and University Representation as presented on table four below. 
Table 1. Respondents' Profile

\begin{tabular}{llcc}
\hline & Value & Frequency & Percentage \\
\hline Gender & Male & 71 & 71.0 \\
& Female & 29 & 29.0 \\
\hline Total & $\mathbf{1 0 0}$ & $\mathbf{1 0 0}$ \\
\hline Below 25 years & 1 & 1.0 \\
& 25-34 years & 37 & 37.0 \\
35-44 years & 35 & 35.0 \\
& 45-55 years & 11 & 11.0 \\
& 56 years and above & 16 & 16.0 \\
\hline Academic Rank & Total & $\mathbf{1 0 0}$ & $\mathbf{1 0 0}$ \\
& Tutorial Assistant & 26 & 26.0 \\
& Assistant Lecturer & 57 & 57.0 \\
& Lecturer & 11 & 11.0 \\
& Senior Lecturers & 5 & 5.0 \\
& Professor & 1 & 1.0 \\
\hline University Representation & Total & $\mathbf{1 0 0}$ & $\mathbf{1 0 0}$ \\
& University of Iringa & 36 & 36.0 \\
& Ruaha University & 34 & 34.0 \\
& Mkwawa University & 30 & 30.0 \\
& College & & $\mathbf{1 0 0}$ \\
\hline
\end{tabular}

Source: (Field Data, 2019)

Results indicate that $71 \%$ males and $29 \%$ female of respondents were participated in the study. This finding revealed that in these three universities there are more male employees compared to female employees. This implies that there is gender imbalance.

Results also indicate opinions from different age groups as shown above. The majority of the employees were between the age of 25 to 44 years, this implies that these universities have a large number of young than other age group so that it will be healthy to invest in training and development for youngsters because these may be used by the organization for quite some time compared to older people. Furthermore, the study found that the majority of staff in these universities are masters holders and lastly on university representation indicates equal representation.

\subsection{Factors affecting academic Staff Retention}

On measuring factors affecting academic staff motivation and retention several dimensions were assessed; these include work environment, promotional practices, Orientation and Induction, 
Feedback system, Recognition and appreciation, Academic staff expectation, training and development, motivation and retention strategies and intention to stay.

Table 2: Motivational and Retention Factors

\begin{tabular}{|l|c|}
\hline Dimension & Weighted Mean \\
\hline Work environment & 3.3 \\
\hline Promotional practices & 3.3 \\
\hline Orientation and Induction & 2.4 \\
\hline Feedback system & 3.02 \\
\hline Recognition and appreciation & 3.16 \\
\hline Academic staff expectation & 2.99 \\
\hline Training and Development & 3.19 \\
\hline Motivation and retention strategies & 2.56 \\
\hline Intention to stay & 2.87 \\
\hline
\end{tabular}

\section{Source: field data (2019)}

As shown in Table 2, work environment, promotional practices, feedback system, recognition and appreciation, training and development have weighted mean above the neutral point (3) while orientation and induction, intention to stay, academic staff expectation and motivation and retention strategies have weighted mean below the neutral point. Out of the nine factors under assessment five of them scored above neutral point (3) explaining the perception of academic staff towards retention and their motivation. The finding of this study is also consistent with the study of Ngirwa, (2005) who said, items in the physical element of an organization can have a positive or negative impact on the organization's ability to attract and retain its employees. If an organization is located in an area with poor housing facilities, poor transport services, employees would normally avoid joining it unless they are exceptionally highly remunerated to cover up for the pertinent inconveniences which have only a short-term effect, therefore, a good physical environment contributes to higher employee morale, productivity, and reduces employee turnover. 


\subsection{Motivational and retention strategies employed by selected universities}

On assessing motivation and retention strategies employed by these universities several issues were considered, these include raise of payment, Improvement of the job security, Timely induction process, Offer appropriate training, Training and development opportunities, Clear career path, Good leadership, Provision of promotion opportunities and Effective management of expectation. Regression analysis was used to assess these strategies;

$\mathrm{X} 1=$ Raise of payment

$\mathrm{X} 2=\mathrm{Job}$ security

$\mathrm{X} 3=$ Timely induction process

X4= Offer appropriate training

X5= Provision of training and development opportunities

X6= Clear career path

X7= Good leadership

$\mathrm{X} 8=$ Provision of promotion opportunities

X9= Effective management of expectation 
Table 3. Regression output motivational and retention strategies employed by selected universities to retain academic staff

\begin{tabular}{|c|c|c|c|c|c|}
\hline & $d f$ & SS & MS & $F$ & Significance $F$ \\
\hline Regression & 9 & 273.1306 & 39.01865 & 35.32509 & $1.86 \mathrm{E}-23$ \\
\hline Residual & 90 & 101.6194 & 1.104559 & & \\
\hline \multirow[t]{2}{*}{ Total } & 99 & 374.75 & & & \\
\hline & & Coefficients & Standard Error & t Stat & P-value \\
\hline Intercept & & 3.9251 & 0.7465 & 5.258 & $9.51 \mathrm{E}-07$ \\
\hline $\mathrm{X} 1$ & & 0.3026 & 0.0444 & 2.3095 & 0.0231 \\
\hline $\mathrm{X} 2$ & & 0.4820 & 0.0362 & 2.2665 & 0.0257 \\
\hline X3 & & 0.1083 & 0.0458 & 2.3668 & 0.0200 \\
\hline$X 4$ & & 0.2196 & 0.0450 & 2.6595 & 0.0092 \\
\hline X5 & & 0.1067 & 0.0519 & 2.0546 & 0.0427 \\
\hline X6 & & 0.5482 & 0.0770 & 3.2242 & 0.0017 \\
\hline X7 & & 0.3482 & 0.0770 & 3.2242 & 0.0017 \\
\hline $\mathrm{X} 8$ & & 0.4263 & 0.0951 & 4.4828 & $2.12 \mathrm{E}-5$ \\
\hline X9 & & 0.1067 & 0.0519 & 2.0546 & 0.0427 \\
\hline Multiple R & & 0.8537 & & & \\
\hline R Square & & 0.728834 & & & \\
\hline Adjusted R Square & & 0.708202 & & & \\
\hline $\begin{array}{l}\text { Standard } \\
\text { Error }\end{array}$ & & 1.05098 & & & \\
\hline Observations & & 100 & & & \\
\hline
\end{tabular}

Source: Field Data 2019

Upon measuring the strategies regression analysis was employed, findings depicts that clear career path, job security, promotion opportunities were found to have a strong effect on academic staff retention with coefficient value of $0.5482,0.4820$ and 0.4263 respectively. These findings imply that majority of the respondents consider these three strategies as important compared to others. The findings are consistent with the study done by Dockel (2003) who strongly argues that people should not only be rewarded financially but they should also be offered opportunities to grow within the organization. Employees who feel stagnant in their positions generally aren't motivated and will not 
stay in unfulfilling position. Promotion offers opportunities for growth and is also one of Herzberg motivators which can be used to enhance retention.

\subsection{Implementation of Retention and Motivation Policies}

The question here was whether academicians are aware of the available motivation and retention strategies as well as the guiding policies, and how do they perceive it. Majority 73\% pointed out that this retention and motivation policies are not implemented according despite their existence. Only $27 \%$ of all respondents agreed that these policies are implemented accordingly; Majority $73 \%$ pointed out that these retention and motivation policies are not implemented accordingly which forced them to quit. It was revealed that these selected universities have strategies on academic staff motivation and retention but unfortunately they have no guiding policies on how to implement those strategies, and others who do have guiding policies they are not clearly communicated to implementers and even academic staff are unaware of them. This contributes a lot in academic staff intention to leave or stay with their current employers.

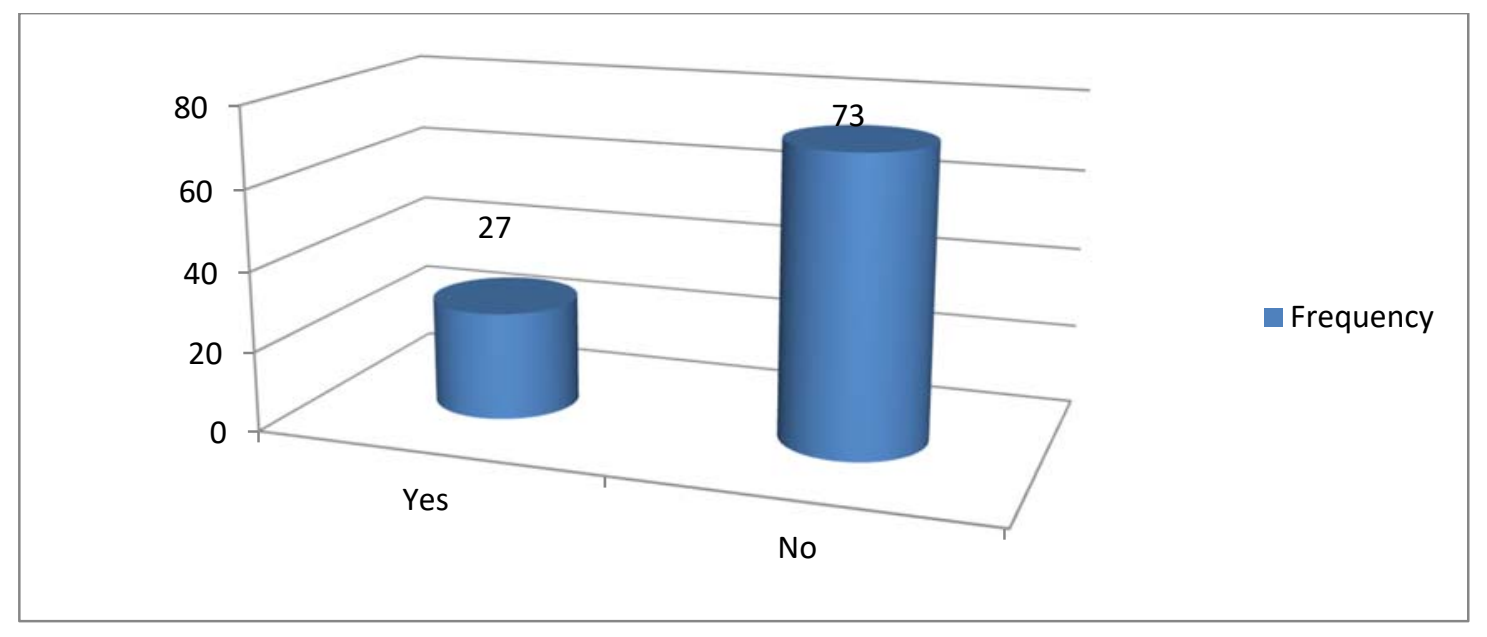

Figure 1. Policies implementation

Source: field data 2019 


\section{Conclusion}

The study concludes that work environment, promotional practices, feedback system, recognition and appreciation, training to influence staff motivation and retention as well as path, job security, promotion opportunities were found to have a strong effect on academic staff retention. Lastly, the majority of respondents declared that retention and motivation policies are not implemented accordingly which forced them to quit.

\section{References}

Al-Omari, et. al. (2009). Faculty Members Intention to Stay in Jordanian Public Universities. International Journal Applied Education Study 1(1). 26-42.

Amutuhaire, T. (2010). Terms of Service and Job Retention among Academic Staff in Makerere University, Master's Thesis, MUST, Kampala.

Armstrong, M. A. (2009). Handbook of Human Resource Management Practice. London: Kogan Page Limited

Bernard, B. (2012). Factors that determine Academic staff Retention and Commitment in Private Tertiary Institutions in Botswana. Research Journal of Management and Business studies, Vol.1(9) pp.278-299.

Bushe, B., Chiwira, O., \& Chawawa, M. (2012). The impact of academic staff recruitment, development and retention policies at Ba Isago University College on their commitment to the College. Research Journal of Business Management and Accounting Vol. 1(4) , pp. 084-097

Chew, J. C. (2004). The influence of Human Resource Management Practices on the Retention of Core employees of Australia Organizations. PhD Thesis .

Daly, et.al. (2006). Greener Pastures: Faculty Turnover Intent in Urban Public Universities. Journal of Higher Education, 77.5 (8/9), 59-64.

Dibble, S. (1999). Keeping Your valuable Employees: Retention strtegies for Your Organisation's Most Important Resource. New York: John Wiley \& Sons. 
Journal of Business Management and Economic Research (JOBMER), vol.3, issue.6, pp.1-14

Dockel, A. (2003). The Effect of Retention Factors on Organisational Commitment: An Investigation of High Technology Employees. Master of Human Resource Thesis. University of Pretoria

Mayer, D. (2006). The changing face of the Australian teaching profession: new generations and new ways of working and learning. Asia-Pacific J. Teacher Educ., 34(1): 57-71.

Metcalf, H., Rolfe, P., \& Weale, M. (2005). Recruitment and Retention of Academic Staff in Higher Education. National Institute of Economic and Social Research.

Naris, N. S., \& Ukpere, I. W. (2010). Developing a retention strategy for qualified staff at the Polytechnic of Namibia. African Journal of Business Management Vol. 4(6) , pp.1078-1084.

Ng'ethe, J.M. (2012). Determinants of Academics Staff Retention in Public Universities in Kenya: Empirical Review. International Journal of Humanities and Social Science, 2(13)

Ngirwa, C. A. (2005). Human Resource Management in Work Organizations. Dar es salaam: National Printing Co.

Oyangi, N. B., \& Kembu, S. A. (2014). To assess the relationship between motivation and retention of academic staff in selected public higher institutions of learning in Dar es-salaam. International Journal of Advancement in Engineering Technology, Management \& Applied Science Volume 1

Samwel, M. O., \& Chipunza, C. (2013). Attrition and Retention of Senior Academic at Institutions of Higher Learning in South Africa: The strategies, Complexities and Realities. Journal of social science $35(2), 97-109$.

Sandhya, K., \& Kumar, P. D. (2011). Employee retention by motivation. Indian Journal of Science and Technology, Vo.12

Tettey, J.W. (2006). Staff Retention in African Universities. Elements of a Sustainable strategy, Washington, DC: World Bank.

Yousaf, A. (2010). One step Ahead: Examining New Predictors of Affective and Organizational Occupational Commitment. PhD thesis. University of Twente.

Zhou, Y., \& Volkwein, J. (2004). Examining the influence s on Faculty Departure Intension: A comparison of tenured Vesus Non-tenured Faculty at Research Universities. Research Higher Learning Centre. 